\title{
ORIENTAÇÃO SEXUAL NA ESCOLA: DIRETRIZES CURRICULARES E ARTICULAÇÃO DOCENTE NO ENSINO FUNDAMENTAL
}

Patrícia Alves Valadares ${ }^{1}$

\begin{abstract}
Resumo: O Presente estudo teve a intenção de averiguar o cumprimento ou não do que prescrevem os Parâmetros Curriculares Nacionais quanto à Orientação Sexual, o seu tratamento de forma transversal e a prática docente. $\mathrm{O}$ objetivo principal do trabalho foi avaliar e como a sexualidade está sendo abordada nas séries iniciais do ensino fundamental, nas escolas da rede pública, localizadas na periferia da Cidade de Montes Claros - MG. Interessa-se compreender a percepção dos professores, sujeitos desta pesquisa, da atual situação da Orientação Sexual nas escolas investigadas. Além disto, interessa-se detectar o preparo destes para o diagnóstico das ações e atitudes apresentadas. Buscou-se, também conhecer as formas como a instituição escola tem abordado o tema sexualidade, e como os alunos têm assimilado tais informações. Esta é um aspecto extremamente importante na formação global das pessoas, sendo assim, não pode ser negada ou ignorada. Daí a relevância de conhecermos os mecanismos criados pela escola para lidar com o tema. Verificou-se que, grande parte dos educadores, não domina as abordagens das Diretrizes apontadas nos Parâmetros Curriculares Nacionais, o que dificulta a dinâmica do trabalho.
\end{abstract}

Palavras-chave: sexualidade, educação, desenvolvimento, infância, personalidade

\section{INTRODUÇÃO}

A questão educacional, além de amplamente discutida, tem-se tornado objeto de diversas considerações, tanto do ponto de vista teórico, quanto das articulações práticas que mantém com a vida social. Face a essas considerações, a escola precisa de abertura para intervir no comportamento da criança, assumindo o que diz a Lei de Diretrizes e Bases da Educação Nacional - 9394/96, quando menciona a formação integral. Esse tema vincula-se ao exercício da cidadania uma vez que propõe o desenvolvimento do respeito a si e ao outro, e contribui para garantir os direitos básicos a todos, como a saúde, a informação e o conhecimento, elementos fundamentais para a formação de cidadãos responsáveis e conscientes de suas capacidades.

Partindo da análise crítica da situação escolar, o presente estudo tem a intenção de refletir sobre a orientação sexual dinamizada em seu contexto. A investigação insere-se no enfoque misto de pesquisa quantitativa e qualitativa no campo da Fenomenologia, cuja proposta é investigar o cumprimento do que prescrevem os Parâmetros Curriculares Nacionais quanto à Orientação Sexual

\footnotetext{
${ }^{1}$ Graduada em Pedagogia pela Universidade Estadual de Montes Claros - UNIMONTES; Mestre e Doutoranda em Educação pela Universidade Católica de Santa Fé - UCSF. Atualmente é Professora nas Faculdades FAVENORTE e FACOMP; Especialista da Educação Básica.
} 
nas Escolas e seu tratamento de forma transversal. O objetivo principal foi verificar como a sexualidade está sendo abordada pelos professores. A problemática da investigação foi: A orientação sexual, nas séries iniciais do ensino fundamental, nas escolas públicas de Montes Claros, é trabalhada de acordo com as Diretrizes Curriculares Nacionais, contribuindo para a formação integral dos alunos?

A investigação foi realizada em escolas públicas da cidade de Montes Claros e, para tal foram utilizados dois instrumentos: uma entrevista semiestruturada, que teve a função de investigar os conhecimentos dos professores em relação ao trabalho com o tema, além de verificar seu grau de espontaneidade acerca das intervenções pedagógicas necessárias durante o processo de formação das crianças; análise do Projeto Político-Pedagógico das Instituições, para verificar a articulação da proposta e sua adequação ao fazer pedagógico dentro da sala de aula.

A discussão foi embasada em posicionamentos de três autores versados no tema: Sigmund Freud (1980), Michael Foulcautl (1990) e Pierre Bourdieu (1975).

Em Freud buscou-se a compreensão para o termo "Sexualidade". Seu posicionamento contribuiu substancialmente para a ampliação da visão, do comportamento e postura social acerca da sexualidade infantil no século XX. Após as descobertas de Freud, a sociedade vem, pouco a pouco, familiarizando-se e compreendendo as diferentes formas de expressão da sexualidade infantil.

Em Pierre Bourdieu, buscou-se respaldo na noção de habitus, que, de certa forma, explica as dificuldades encontradas pelos professores para mudar uma prática que vem sendo construída há muito tempo sobre o trabalho com a sexualidade na escola.

Na perspectiva de Foulcault, buscaram-se reflexões sobre o discurso - não só o discurso daquilo que é dito, mas também o não-discurso, o não-dito, o excluído do discurso. Segundo ele, toda exclusão discursiva desafia o nosso compromisso com a verdade. Foulcault questiona a onipotência do discurso e, ao mesmo tempo sua fragilidade.

\section{EDUCAÇÃO SEXUAL: CONCEITOS, PROCESSOS E PRÁTICAS SOCIAIS}

A economia mundial encontra-se em acelerado processo de globalização. Grandes volumes de capital migram de um país para outro, com a velocidade das telecomunicações, em busca de melhores oportunidades. As fronteiras econômicas vão perdendo o significado, e a função que tiveram até hoje, ou seja, a idéia de desenvolvimento nacional autônomo já não faz mais sentido. $O$ elemento fundamental e decisivo de todo este quadro é a acelerada mudança de paradigma em curso, no momento. 
A noção de desenvolvimento está atrelada a um contínuo de evolução, em que o indivíduo caminha ao longo de todo o ciclo de vida. Essa evolução, nem sempre linear, dá-se em diversos campos de existência, tais como afetivo, cognitivo, social e motor.

Esse caminhar contínuo não é determinado apenas por processos de maturação biológicos ou genéticos. O contexto sócio-cultural é fator de máxima importância no desenvolvimento humano. Na visão de Vygotsky(1998), os seres humanos nascem "mergulhados em cultura", e é claro que esta será uma das principais influências no desenvolvimento. Embora ainda haja discordâncias teóricas entre as abordagens sobre o grau de influência da maturação biológica e da aprendizagem com o meio no desenvolvimento, o contexto cultural é o palco das principais transformações e evoluções do seres humanos. Pela interação social, aprendemos e nos desenvolvemos, criamos novas formas de agir , ampliando nossas ferramentas de atuação neste contexto complexo, durante todo o ciclo vital.

Durante todo esse processo, a educação básica assume um papel de transcendental importância. Sendo assim, a escola deve buscar acompanhar essa transformação histórico-social para atender às necessidades dos alunos na construção de sua identidade como pessoa e cidadão atuante e participativo. Isso significa que deve incorporar em sua prática a educação afetivo-sexual, cujos alicerces se firmam numa visão de mundo, de pessoa e de educação, que, assumida como referência teórica, inspira uma postura ética de compromisso com a formação integral do educando.

Não se pode negar ou simplesmente ignorar a sexualidade. Ela existe e faz parte do nosso diaa-dia. Está inserida nas sociedades do mundo inteiro e apresenta-se sob as formas mais diversificadas e, para cada uma delas, existe um conjunto de variáveis físicas, mentais e psico-sociais que contribuem para a formação integral das pessoas.

A educação sexual é, na realidade, um processo e um sistema de transmissão de conhecimentos, e exerce influências no desenvolvimento e na vida psíquica das pessoas, pois, além de sua potencialidade reprodutiva, relaciona-se com a busca do prazer, que é uma necessidade fundamental. Manifesta-se desde o momento do nascimento até a morte, de formas diferentes a cada etapa do desenvolvimento humano, sendo construída ao longo da vida.

Indissociavelmente ligado a valores, o estudo da sexualidade reúne contribuições de diversas áreas, como Educação, Psicologia, Antropologia, História, Sociologia, Biologia, Medicina e outras. Se, por um lado, sexo é uma expressão biológica que define um conjunto de características anatômicas e funcionais (genitais e extragenitais), a sexualidade entendida de forma bem mais ampla é expressão cultural. Cada sociedade desenvolve regras que constituem parâmetros fundamentais para o comportamento sexual das pessoas.

O Dicionário de Psicanálise (1981) define a sexualidade não somente como um prazer dependente do funcionamento da parte genital e, sim, a toda uma série de excitações que envolve o 
ser humano desde a infância, não podendo ser reduzida à satisfação de uma necessidade fisiológica, como, por exemplo, alimentar, respirar, dormir.

Como é sabido, a psicanálise atribui uma grande importância à sexualidade no desenvolvimento da vida psíquica do ser humano. Ao se falar em sexualidade infantil, pretende-se reconhecer não somente a existência de excitações ou de necessidades genitais precoces, mas também a busca de satisfação de um prazer, como, por exemplo, a sucção. Nesse sentido, os psicanalistas falam das fases da vida em que atitudes sexuais são pertinentes, como a fase anal e a fase oral.

Essa ampliação do campo da sexualidade nos remete inevitavelmente a Freud para entender a relação humana, estabelecida entre o sujeito/sujeito, sujeito/objeto de desejo, sujeito/contexto social.

Para Freud (1980), a maneira como somos, como pensamos, como nos vemos e como nos comportamos é produto de uma relação entre consciente e inconsciente. Somos, portanto, dirigidos por determinações alheias a nossa vontade, por serem comandadas por nosso eu interior. $\mathrm{O}$ funcionamento intelectual da criança é regido pela tensão entre o princípio do prazer e o princípio da realidade, isto é, pela busca inconsciente do prazer ilimitado e pelos limites da realização possível.

Segundo Mielnik (1990, p. 15), "como todo e qualquer setor da cultura humana, o setor do sexo torna-se necessário à intervenção do ambiente educativo, estabelecendo-se, assim, as fontes e causas do sistema educativo peculiar a cada criança”. De um lado, encontramos a sociedade organizada, empenhada em transmitir à criança conhecimentos certos ou errôneos (noções, imagens, superstições, ameaças, crendices, boatos, informações) referentes ao sexo; do outro, teremos a criança seguindo as próprias inclinações e pendores de sua personalidade.

O alvo desejado no preparo sexual da criança é o de conseguirmos que o indivíduo obtenha um desenvolvimento psico-sexual normal, atingindo a maturidade com bom ajustamento sexual. A escola, por sua vez, não está apenas encarregada de transmitir instrução: ler, escrever e contar, mas também é responsável por formar grande parte de sua personalidade, e todos reconhecem a influência importantíssima do professor sobre seus alunos.

O respeito que votamos ao corpo humano não deve excluir os órgãos genitais e os fenômenos biológicos da fecundação. A criança deve aprender a considerar os órgãos genitais com a mesma seriedade e importância direcionada a outros órgãos. Sendo assim, não deve haver embaraço ou timidez em se tratando de perguntas que abordem regiões do corpo humano. Não respondendo com escassez nem exagero ao que foi perguntado, está-se instruindo a criança, o que abordará uma noção justa e comedida da importância, seriedade e respeito com que se deve encarar os assuntos do sexo. Jamais se deve prejudicar a pureza infantil desrespeitando sua avidez de saber ao se ignorar a forma, totalmente isenta de maldade, como pergunta. 
Muitas manipulações e experiências infantis, no terreno sexual, são consideradas como manifestação de imoralidade, indecência, taras ou vícios sexuais. Segundo Isaac Mielnik (1990, p. 24), “tal atitude é digna de lástima, pois demonstra ignorância e pode traumatizar o bom desenvolvimento da criança. Freqüentemente, tais manipulações, apalpações e experiências não passam de fases transitórias e normais do processo de desenvolvimento psico-sexual infantil”. Essas atividades devem ser consideradas e valorizadas pelo que realmente significam, não apresentando as implicações sexuais que teriam os mesmos atos, se praticados por adultos. Muito se poderia conseguir, se os educadores procurassem melhorar suas fontes de conhecimentos, passando a encarar tais situações infantis com naturalidade.

É muito interessante para a criança praticar a autoanálise, conhecer o seu corpo, as suas sensações. O sexo não é, certamente, o único ou o mais importante setor a vida humana, contudo é bastante necessário e destacado para fazer parte na formação de uma personalidade sadia e equilibrada (MIELNIK, 1990).

A educação sexual contribui para manter elevados os princípios da ética, da moral e do respeito humano, além de buscar o equilíbrio entre a valorização do prazer e a ação cooperativa e voluntária. Aprendendo a conviver, sabendo de que maneira ajudar os demais, organizando-se em ações voluntárias para atender a uma causa justa, o aluno estará aprendendo a dar voz ativa, ainda que simbólica, a seus sonhos e a seus devaneios, o que contribuirá para uma ampla compreensão da realidade onde está inserido.

\section{INFÂNCIA E SEXUALIDADE: UM OLHAR CUIDADOSO}

Os contatos de uma mãe com seu filho despertam nele as primeiras vivências de prazer. Essas primeiras experiências sensuais de vida e de prazer não são essencialmente biológicas, mas se constituirão no acervo psíquico do indivíduo; são o embrião da vida mental do bebê . A sexualidade infantil se desenvolve desde os primeiros momentos de vida e segue manifestando-se de forma diferente em cada momento da infância.

Inicialmente, Freud acreditava que a sexualidade humana só se desenvolvia na puberdade, período em que o organismo poderia procriar. Entretanto, ele começou a rever essas questões com estudos sobre a sexualidade infantil. As pulsões sexuais são vividas livremente pelas crianças e experimentadas à parte, não havendo ainda um objeto sexual. A pulsão sexual, tal como vemos em ação em um adulto, é composta de pulsões parciais, cuja ação se observa nas preliminares do ato sexual. Cada pulsão se liga ao prazer extraído do órgão a que estiver vinculado. A título de ilustração, podemos citar: olho, no caso da contemplação; genital próprio, no caso da masturbação; boca, no caso da sucção do polegar; ânus, no caso da defecação (KUPFER, 1997). 
Entretanto, na ausência do objeto sexual, a pulsão sexual não possui outros fins senão os propriamente sexuais e é passível de sublimação. É aí que interessa ao educador, cuja interferência, segundo Freud, terá seu papel primordial. É muito comum crianças ainda bem pequenas descobrirem o prazer na manipulação do próprio corpo. Os adultos devem ter em mente que a masturbação é normal e faz parte do processo do autoconhecimento. Realmente é difícil lidar com situações como essas. Não se deve olhar os atos infantis comparando-os com os dos adultos. A criança não faz nenhuma relação com o "sexo em si", ela apenas sente prazer. Mais tarde poderá sentir-se culpada por ter sido desaprovada, e essa culpa poderá ser levada para sua própria experiência sexual.

A criança que tem idade para perguntar também tem idade para ouvir. Os pais nunca devem dar respostas imaginárias e irreais, como, por exemplo: se a criança perguntar como nasceu, e o pai responder que foi a cegonha que trouxe, ao invés de falar a verdade, na linguagem adequada para cada idade. Freud coloca os pais como pessoas incompetentes para a tarefa da educação sexual, preferindo que eles não se ocupem dessa tarefa. Para ele, os pais esqueceram-se da sexualidade infantil e, se esqueceram, é porque houve repressão (KUPFER, 1997). Se houve repressão, inevitavelmente algum recalque ainda permanece.

Pais que tiveram uma educação rígida normalmente possuem dificuldade em lidar com esse tipo de assunto. Muitos possuem uma sexualidade problemática, mal resolvida e não sabem como ajudar seus filhos. Na visão de Suplicy(1983), a grande maioria dos pais busca uma receita, uma resposta fácil para baixar sua ansiedade diante da situação que estão vivendo. No entanto, se por um lado podemos encontrar aqueles pais que fingem nada estar acontecendo, com receio de enfrentar a situação, de outro estão os superprotetores, que querem saber tudo sobre o filho. Os pais devem ter em mente que não existe uma receita pronta. Para falar de sexo com crianças, é preciso, antes de tudo, criar um ambiente favorável, onde ele se sinta seguro, tendo liberdade sem correr o risco de ser reprimido.

Foulcault (1990), demonstrou como funcionaram e funcionam as práticas discursivas: ora estimulando, ora reprimindo as práticas sexuais. O sexo e seus efeitos são fáceis de decifrar; em compensação, sua repressão pode ser mais facilmente analisada. E a causa do sexo, sua liberdade e o direito de falar dele encontram-se ligados à causa política.

Os temas trazidos por Foucault (1994), entre eles o discurso, o dito e o não dito, a hipótese repressiva são importantes para analisar a implantação do tema transversal relacionado à sexualidade nas escolas, uma vez que o falado, assim como o silêncio, escondem e evidenciam práticas adotadas nas escolas por alunos e professores em relação ao tema "sexualidade". É nesse sentido que, de um modo geral, os pais precisam ficar atentos aos discursos que são dirigidos a seus filhos, no intuito de não reprimir as linguagens que expressam sua sexualidade. 


\section{SEXUALIDADE SEGUNDO OS PARÂMETROS CURRICULARES NACIONAIS: A VALORIZAÇÃO DOS TEMAS TRANSVERSAIS}

Os Parâmetros Curriculares Nacionais são documentos estabelecidos como norteadores do Sistema Educacional Brasileiro, pela Lei de Diretrizes e Bases da Educação Nacional 9394/96. Abordam, em um documento específico, o tema "Orientação sexual" como tema transversal a ser trabalhado a partir das séries iniciais do ensino fundamental, abordando uma temática muito associada à quebra de preconceitos, crenças, tabus ou valores singulares. Para que o trabalho possa se efetivar de forma coerente com a visão pluralista, é necessário que as diferentes crenças e valores, as dúvidas e os questionamentos sobre diversos aspectos ligados à sexualidade encontrem espaço para se expressar.

O ponto de partida é um curso inicial, que aborda os passos básicos para a implantação de trabalhos que enfoquem Orientação Sexual nas escolas, incluindo postura, metodologia, aspectos biológicos, psicológicos e temas sociais polêmicos. Procura gerar reflexão, ajudando o educador a lidar com suas dificuldades, barreiras e preconceitos frente ao tema da sexualidade. Trata, também, de discutir a sexualidade na infância e na adolescência e procura trabalhar dinâmicas de atuação em sala de aula. Supõe um trabalho contínuo, sistemático e regular, que acontece ao longo de todo o processo escolar. Deve começar na Educação Infantil e se estender até o final do Ensino Médio. Pressupõe a capacitação, reciclagem e acompanhamento do trabalho dos educadores, caracterizando um espírito de formação permanente.

Segundo os PCN's (1997), deve-se articular a abordagem do tema por meio de diálogo, reflexão e da possibilidade de reconstruir informações, pautando-se sempre pelo respeito a si próprio e ao outro. Para isso, o documento viabilizou o tema por meio da transversalidade, que significa que a concepção, quanto aos objetivos e conteúdos propostos pelo tema, encontram-se contemplados por diversas áreas do conhecimento. Dessa forma, estará impregnando toda a prática educativa. Cada uma das áreas tratará da temática por meio de sua própria proposta de trabalho. Ao se apresentarem os conteúdos de Orientação Sexual, serão explicitadas as articulações mais evidentes de cada bloco de conteúdo com as diversas áreas.

O trabalho de Orientação Sexual implica o tratamento de questões que nem sempre estarão articuladas com as áreas do currículo - seja porque trata de questões singulares que necessitam de um tratamento específico, seja porque permeiam o dia a dia na escola das mais diferentes formas, surgindo de maneira emergente e exigindo do professor flexibilidade, disponibilidade e abertura para trabalhar tais questões.

As indicações e propostas dos PCN's representam mais um desafio para a escola, que, até então, trabalhava, na maioria das vezes, de forma descomprometida e desvinculada da realidade. Os 
Parâmetros buscam também romper com essas concepções e práticas tradicionais e com a visão de que o aluno chega à escola como um ser inanimado, como uma folha em branco, sem conhecimentos advindos de sua experiência existencial, o que denota, provavelmente, que existem possibilidades para a construção de um trabalho educativo que contemple as diferenças e que contribua para formar cidadãos inseridos e comprometidos com o meio em que vivem, visualizando possibilidades de transformá-lo.

Conseqüentemente, no Ensino Fundamental, os PCN's preconizam que a abordagem do tema precisa contribuir para que ocorra a valorização dos conhecimentos que a integram na dimensão de que são essenciais também para a formação do cidadão. E, ainda, preconizam que precisa ser valorizada a pluralidade de etnias existente no Brasil, reconhecendo-se a diversidade de traços, crenças, saber e fazer, o que expressa a necessidade da inserção desta pluralidade no processo ensinoaprendizagem.

A proposta dos Parâmetros é que a Orientação Sexual oferecida pela escola aborde as repercussões de todas as mensagens transmitidas pela mídia, pela família e pela sociedade. Trata-se de preencher lacunas nas informações que os alunos possuem e, principalmente, criar a possibilidade de formar opinião a respeito daquilo que lhe foi apresentado. A escola, ao oferecer tais informações, possibilita ao aluno desenvolver atitudes coerentes com os valores que ele próprio elegeu como seus.

De acordo com Araújo (2003), há três formas diferentes de se entender a relação entre os conteúdos tradicionais e os transversais. Uma primeira forma seria que essa relação deve ser intrínseca, ou seja, não tem sentido haver distinções claras entre conteúdos tradicionais e transversais. Um professor de matemática, por exemplo, jamais poderia trabalhar o seu conteúdo de matemática desvinculado da construção da democracia e da cidadania. A segunda maneira seria entender que a relação entre disciplinas tradicionais e transversais pode ser feita pontualmente, através de módulos ou projetos específicos, com os quais os professores de diferentes áreas abririam espaço para algum tema transversal em suas aulas. Uma terceira maneira seria integrando interdisciplinarmente os conteúdos tradicionais e os temas transversais, ou seja, entendendo que a transversalidade só faz sentido dentro de uma concepção interdisciplinar de conhecimento.

O que essas três formas de conceber o trabalho transversal na educação têm em comum é que todas defendem a concepção de manutenção das disciplinas curriculares como eixo longitudinal do sistema educacional, cabendo aos temas transversais girar em torno desse eixo ou impregná-los.

Na obra Temas Transversais em Educação: Bases para Uma Formação Integral, Busquets et al. (2000) trazem grandes contribuições para a compreensão das origens dos Temas Transversais na educação. Os Temas Transversais foram discutidos originalmente na Espanha, onde foram publicadas obras de referência para os educadores interessados em conhecer as origens da estrutura curricular das escolas ocidentais e, ao mesmo tempo, entender o significado do conceito de transversalidade. A 
discussão a respeito dos temas transversais na educação surge de questionamentos realizados por alguns grupos politicamente organizados em vários países sobre o papel da escola dentro de uma sociedade plural e globalizada e sobre os conteúdos que deveriam ser abordados nessa escola. Agora, essa discussão também faz parte do cotidiano dos educadores brasileiros. Nessa perspectiva, vê-se na escola uma porta aberta para que problemas e práticas sociais sejam tratados com o intuito de se garantir a igualdade de direitos para todos. Portanto, a educação escolar, hoje, não é apenas ensinar o aluno a ler e a escrever, como outrora se fazia, mas educar para a cidadania.

Para a escola atingir essa nova função social, torna-se necessária a inclusão dos Temas Transversais na estrutura curricular da escola. $O$ tratamento desses temas deve ocorrer de forma sistematizada e organizada, de maneira que sejam abordados seus aspectos conceituais, procedimentais e atitudinais.

Para Busquets et al. (2000), a interdisciplinaridade envolve perceber que um conhecimento mantém um diálogo constante com outros conhecimentos, pois não estão fragmentados. Em algum ponto eles estabelecem relação de aproximação entre si.

A abordagem dos Temas Transversais requer que essa nova prática pedagógica passe também a existir na sala de aula, em que as partes de um todo precisam ser estudadas e compreendidas no seu conjunto, onde a existência de um elemento justifica e explica a existência e o funcionamento de outro elemento, numa visão que comporta os conhecimentos construídos nas várias disciplinas.

Portanto, as disciplinas escolares envolvem conhecimentos que devem ser abordados de maneira integrada, numa visão global que permita ao aluno ver o mesmo objeto de conhecimento sob várias perspectivas. A interdisciplinaridade deve ser vista como eixo integrador de todas as disciplinas, permitindo compreender um fenômeno sob vários pontos de vista.

A reforma do Ensino Fundamental prevê uma abordagem pedagógica que facilite a ponte entre a teoria e a prática e, nessa perspectiva, deve-se trabalhar o conteúdo científico de forma contextualizada, retirando o aluno da condição de espectador, envolvendo-o no estudo participativo de dimensões tanto da vida pessoal, como da social e da cultural. Trabalhar com o conhecimento contextualizado implica ter que abordar os temas transversais no processo de ensino e aprendizagem.

Segundo Yus (1998, p. 24), "a escola necessita se abrir para a vida, deixar-se penetrar por ela, empapar-se de sua realidade e fundamentar toda a sua ação nessa realidade cotidiana”. Nesse sentido, o cotidiano do aluno deve ser visto como um conjunto de conhecimentos importantes, que deverá ser utilizado pelo professor como ponto de partida e suporte para subsidiar o tratamento do conteúdo curricular. Buscar a interface conteúdos curriculares/cotidiano do aluno traz uma grande riqueza para o processo ensino-aprendizagem, além de motivar o aluno a uma aprendizagem sólida e com significados reais. 


\section{EDUCAÇÃO SEXUAL NA ESCOLA: O PAPEL DOS EDUCADORES VERSUS PRÁTICA DOCENTE}

A educação escolar não pode selecionar setores de atividade. Deve ser, antes de tudo, uma educação integral, unitária. A Orientação Educacional desenvolve papel de articulação e interação entre toda a comunidade escolar, observando-se, ainda, sua atuação como elemento integrante do grupo de gestão escolar, no processo de desenvolvimento do projeto político-pedagógico. Ressaltase que é imprescindível um trabalho de conhecimento e reconhecimento das demandas sociais, políticas que interferem nas relações e organizações de vida dos alunos. Nesse sentido, ao Orientador Educacional compete organizar o processo educativo pedagógico integrado à realidade sócio-cultural, favorecendo o desenvolvimento do ser cidadão.

A percepção e a leitura são ponto de partida para a análise, porém faz-se necessário, ainda, intervir, projetar e planejar ações que contribuam para a construção deste "ser social". Nenhuma informação solicitada pelas crianças deve ou pode ser ignorada pelos professores. Assim como se ensina Ciências ou Matemática, com simplicidade e honestidade, também deve ser ensinada a sexualidade. Como se fala em respiração, digestão, circulação, pode-se e deve-se falar de produção, como sadia satisfação da curiosidade inata a respeito da origem humana e de seu desenvolvimento.

Sob outro prisma, a escola deve tomar a si parte da formação moral das crianças. Os professores transmitem aos alunos muito de si mesmos: hábitos, filosofia de vida, crendices, tabus, o que reporta ao currículo oculto, ou seja, ao que não está explícito nos programas ou currículos formais. Devem também buscar a efetivação de uma educação escolar numa perspectiva verdadeira em todos os sentidos.

Considerando esses aspectos, constantemente surgem novidades no campo da orientação sexual, contrapondo-se à situação antiga, em que havia unanimidade de teorias e atitudes. O professor das séries iniciais, mercê de sua situação ímpar, como técnico em pedagogia, interessado na formação dos seus alunos, vê-se constantemente solicitado a funcionar como orientador em inúmeras situações e vivências psicológicas da vida cotidiana. Na verdade, essas situações não fogem as de ordem sexual, em que o professor fará valer seu bom senso e seu respeito pela criança, para fornecer esclarecimentos que contribuam para a melhoria e desenvolvimento do espírito dela.

"A educação sexual que a criança recebeu em casa traz o cunho, a marca, a propriedade específica e particular dos pais.(...) Os pais educam as crianças quase sempre a partir do ponto de vista "subjetivo": meu filho, minhas ideias, o que eu acho, o que eu penso, etc". O professor formador deve encarar as situações de modo "objetivo". Sua orientação visa, pois, o preparo da criança, não dentro de uma situação subjetiva e específica e, sim, geral, ampla e principalmente levando em conta o contexto social. A escola funciona como uma pequena sociedade, e as relações infantis escolares podem ser consideradas como o embrião de reações e atitudes sociais. (Mielnik,1990, p.22) 
Os professores devem evitar emitir seus próprios juízos de valor e opiniões como verdades absolutas. Sabemos que é impossível ficar totalmente isentos de opinar, e nem devemos, mas é importante que as questões sejam lançadas, refletidas, discutidas, sem que apenas uma resposta fique como a correta. Esclarecer os limites também faz parte do papel do orientador, que deve mencionar algumas questões importantes como o que se pode fazer em locais públicos e privados para que a intimidade seja preservada. Isso cabe principalmente às crianças que ainda não possuem essa noção bem definida.

Deve existir também uma efetiva parceria, ou seja, os pais não devem delegar e restringir este assunto apenas ao âmbito escolar. Nesse sentido, é necessário que a escola dê um retorno aos pais do que está sendo visto, as reações dos alunos, temas que estão em pauta, convite para assistirem a debates juntamente com os alunos; e esteja sempre aberta aos pais para orientá-los no caso de não saberem como lidar com os questionamentos dos filhos.

Educação sexual não significa apenas passar informações sobre sexo. Significa também o contato pessoa-pessoa, transmissão de valores, atitudes, comportamentos. É importante observar se esses educadores estão preparados psicologicamente para falar sobre sexo, já que muitos não possuem a própria sexualidade bem resolvida, tendo problemas ou angustias em relação ao sexo. Assim, em seu discurso, certamente passarão um tom de frustração e inquietação. As pessoas encarregadas de orientação sexual na escola devem ter autenticidade, empatia e respeito.

A escola na sociedade escolarizada é um locus cultural extremamente importante para a definição dos rumos do desenvolvimento, e a intervenção pedagógica é essencial na definição do desenvolvimento do sujeito. Ao trabalhar a totalidade do aluno, além de considerar sua relação com a escola e a sociedade, com seus determinantes econômicos e políticos, é relevante contemplar a dimensão da sexualidade infantil, negada historicamente. A escola deve propiciar interações necessárias para que a sexualidade se desenvolva em uma dimensão afetiva e prazerosa, rompendo com a tradição judaico-cristã de negação do corpo e dos desejos. É preciso usar a Pedagogia do bom senso, tão discutida por Paulo Freire. É preciso estar atento ao que falar, como apresentar, discutir e "mexer" com questões muitas vezes trazidas através da história de vida dos alunos e do próprio professor.

De acordo com Edward Murray (1971), a emoção pode ter tanto efeitos organizadores como desorganizadores sobre o comportamento. Pode perturbar o comportamento corrente, mas pode também gerar novas formas de comportamento, no sentido do objetivo. Não se pode ignorar que as reações emocionais em termos de organismo são aprendidas, ou seja, a cultura escolhe algumas formas mais adequadas a determinadas situações ou tipo de pessoas (idade, sexo, posição social). 
Trabalhar com Orientação Sexual implica ampliar um conhecimento mais profundo dessas questões. O desenvolvimento do trabalho não pode ser de forma meramente conteudista ou informativa, pois se faz necessário reconstruir e ter um entendimento maior de nossas próprias crenças e valores, de nossos conceitos e preconceitos, trabalhar um novo olhar. Entender o processo histórico e social que trouxe para a escola a temática, mesmo que seja de forma transversal.

O papel do professor no processo de Orientação Sexual é muito importante, pois não se restringe apenas ao domínio de uma área ou campo de conhecimento. Desse modo, é necessário ter acesso à formação específica para tratar de sexualidade com crianças e jovens na escola, possibilitando a construção de uma postura profissional e consciente no trato desse tema. Os professores necessitam entrar em contato com suas próprias dificuldades diante do tema, com questões teóricas, leituras e discussões referentes à sexualidade e suas diferentes abordagens. A formação deve ocorrer de forma continuada e sistemática, propiciando a reflexão sobre valores e preconceitos dos próprios educadores envolvidos no trabalho de Orientação Sexual.

Na percepção de Kupermann (1999), o professor precisa dispor do acolhimento suficiente de modo a permitir a emergência da confiança necessária à abordagem franca das questões e dificuldades vividas no âmbito da sexualidade. É importante que reconheça como legítimas e lícitas, por parte das crianças e dos jovens, a busca do prazer e as curiosidades manifestas acerca da sexualidade, uma vez que fazem parte de seu processo de desenvolvimento. Isso significa que, para a realização de um consistente trabalho de Orientação Sexual, é necessário que se estabeleça uma relação de confiança entre os envolvidos. Os professores precisam se mostrar disponíveis para conversar a respeito dos temas propostos e abordar as questões de forma direta e esclarecedora, exceção feita às informações que se refiram à intimidade do educador. Informações corretas do ponto de vista científico ou esclarecimentos sobre as questões trazidas pelos alunos são fundamentais para seu bem-estar e tranquilidade, para uma maior consciência de seu próprio corpo e elevação de sua autoestima.

A obra "A Reprodução", de Bourdieu e Passeron (1975), mostra como a escola está organizada para produzir as concepções, os valores, enfim, a ideologia dos grupos sociais dominantes, de uma tal maneira que todas as atividades pedagógicas que se realizam no âmbito do aparelho escolar estariam condenadas a contribuir para o fortalecimento da ordem social em vigor. Esses autores nos mostram que a escola não é uma instituição neutra, mas, sim, uma estrutura a serviço das classes dominantes - o que se pode perceber pela análise dos conteúdos que ela privilegia

Uma das grandes preocupações que esses dois autores têm tido com o sistema de ensino está relacionada à dimensão social que esse sistema fornece para a formação de um habitus. Em suas palavras: 
(habitus) são sistemas de disposições duráveis e transferíveis, estruturadas e estruturantes do agente ${ }^{2}$. O habitus, enquanto produto da história, orienta as práticas individuais e coletivas. Ele tende a assegurar a presença ativa das experiências passadas que, depositadas em cada indivíduo sob a forma de esquema de pensamento, percepção e ações, contribuem para garantir a conformidade das práticas e sua constância através do tempo (Bourdieu e Passeron, 1975, p. 61).

A cultura escolar, na condição de uma das agências formadoras do habitus, propicia aos indivíduos a ela submetida um corpo comum de categorias de pensamento, de código comum, de percepção e apropriação que tendem a funcionar como forma de classificação dos homens e das coisas. O saber escolar separa os indivíduos que estiverem expostos à ação daqueles que, por razões diversas, foram excluídos de sua influência sistemática e contínua. Isso significa dizer que o sistema escolar proporciona aos sujeitos muito mais do que esquemas de pensamentos particulares e distintos; oferece um sistema complexo de disposições, capaz de funcionar como estruturas classificatórias, possíveis de serem aplicadas nas mais diversas situações.

Segundo Bourdieu (1975), Habitus é o conjunto de disposições estruturantes no agente, segundo a maneira pela qual ele interiorizou as estruturas objetivas que viveu num processo de socialização determinado. Essas disposições estruturam as categorias de percepção que, por sua vez, orientam a ação do agente. A capacidade de determinação do habitus sobre o comportamento do agente é ainda maior quando ele se encontra inserido em estruturas objetivas compatíveis com o habitus interiorizado, o que reforça sua estruturação. Em contrapartida, um habitus interiorizado durante um dado período de socialização pode ser reforçado ou enfraquecido por outros processos vivenciados pelo agente.

Segundo Ortiz (1980), Bourdieu descreve os mecanismos pelos quais a escola mantém a herança cultural e compreende, assim, o fracasso e o sucesso escolar, deixando de tratar como dons naturais aquilo que é assimilado culturalmente.

Ao abordar os fundamentos teóricos de Bourdieu para o campo escolar, observa-se que existe uma nítida diferença entre as perspectivas dos alunos e as dos professores quanto ao tema sexualidade. Aquilo que os alunos necessitam receber como orientação sexual não está sendo feito pelos professores, que, de certa forma, detêm o controle do processo pedagógico na escola.

Através da pesquisa realizada, detectamos uma grande dificuldade dos docentes em lidar com as manifestações acerca do tema sexualidade e, mesmo sem querer, transmitem aos educandos seus preconceitos, ao mesmo tempo em que se limitam a falar do sexo apenas como função reprodutiva, deixando de lado as outras formas de manifestação da sexualidade.

\footnotetext{
${ }^{2}$ Bourdieu utiliza a denominação "agente” em lugar de "indivíduo".
} 
Ao se tratar das concepções dos profissionais entrevistados, observaram-se divergências quanto à sua articulação pedagógica em relação ao tema sexualidade no espaço escolar e as respostas dadas. Em relação aos objetivos investigados, levantamos os seguintes pontos sobre os entrevistados e sua prática dentro da sala de aula, de acordo com as hipóteses do trabalho:

a) a respeito da percepção dos entrevistados quanto à influência do desenvolvimento da sexualidade para a formação da personalidade do indivíduo, 90\% dos profissionais investigados consideram de grande importância para a formação de uma personalidade equilibrada; apenas $10 \%$ disseram que acreditam ser importante até certo ponto; para eles a sexualidade deve levar em conta a maturidade da criança. Caso não seja necessário, o professor não deve evidenciar o tema para não despertar o interesse das crianças;

b) quanto à postura mais freqüente dos educadores frente às manifestações e dúvidas de seus alunos em relação à sexualidade, $75 \%$ dos entrevistados demonstraram ter dificuldades na abordagem do tema, sentem-se inseguros, pouco à vontade, o que indica uma postura inflexível em relação ao sexo e à sexualidade. A naturalidade anunciada em algumas respostas pelos professores fica apenas no âmbito do discurso, ou seja, não é transportada para a prática pedagógica dentro da sala de aula;

c) a respeito da compreensão dos entrevistados acerca dos PCN`s, a pesquisa revelou uma má formação por parte dos docentes para o desenvolvimento desse tipo de trabalho com os alunos, e muitos deles acabam usando o temor pelas famílias dos alunos como justificativa para o não desenvolvimento do tema em sala de aula. Quanto à compreensão acerca das diretrizes educacionais propostas pelo PCN`s, constatamos que 15\% dos entrevistados demonstraram ter conhecimento; $35 \%$ demonstraram não ter nenhuma compreensão, e 50\% revelaram compreender muito pouco;

d) quanto à aplicação dos PCN`s dentro da sala de aula, a pesquisa demonstrou que apenas $10 \%$ dos entrevistados compreendem a proposta de trabalho, em especial o volume 10, que aborda a "Orientação Sexual". Constatou-se que todos os professores que compreendem a proposta aplicam as diretrizes em sala de aula. Os professores que não conhecem ou não compreendem a articulação pedagógica dos PCN's, consequentemente não a aplicam;

e) $90 \%$ dos professores investigados não entendem verdadeiramente o conceito de transversalidade e não conseguem realizá-lo no contexto da Orientação Sexual;

f) mesmo não compreendendo as propostas curriculares evidenciadas pelos PCN's, todos os entrevistados disseram que não é possível ignorar a sexualidade da criança e dar ênfase às demais habilidades, em especial ao desenvolvimento cognitivo. Disseram que a sexualidade faz parte do desenvolvimento integral do indivíduo, sendo assim precisa ser direcionado dentro da escola. Isso demonstrou incoerência com o primeiro item da entrevista, o que comprova pouca segurança na abordagem do tema. 
Ao contrário da prática predominante, a escola deve informar, problematizar e debater os diferentes tabus, preconceitos, crenças e atitudes existentes na sociedade, buscando não a isenção total, o que é impossível, mas um maior distanciamento das opiniões e aspectos pessoais dos professores para empreender essa tarefa. Isso porque, na relação professor-aluno, o professor ocupa lugar de maior poder, constituindo referência para o aluno.

\section{CONSIDERAÇÕES FINAIS}

A sociedade atual vem passando por um contínuo processo de mudança estrutural em direção à sociedade da informação. Nesse contexto, a sexualidade infantil ganha cada vez mais espaço nas discussões e estudos científicos. Ela é fundamental para a formação da personalidade, pois é uma necessidade básica do ser humano, estritamente relacionada aos pensamentos e ações. As instituições sociais, dentre elas a instituição escolar, ajudaram a validar representações e discursos acerca da sexualidade; assim, é importante ressaltar que os sujeitos envolvidos nesse processo não cumprem aquilo que é prescrito através desses discursos. Isso foi claramente observado durante as entrevistas, nas posturas adotadas pelos professores.

Foucault questiona as práticas discursivas, não somente daquilo que é dito, mas também o excluído do discurso. De acordo com sua fala podemos dizer que, quando a instituição escolar observa comportamentos ou conceitos adquiridos que não se enquadram em padrões aceitáveis e não se pronuncia perante tal, esta se torna omissa, o que reforça este mesmo comportamento. Além disso, Foucault questiona a onipotência do discurso e chama de "hipótese repressiva" as perspectivas de análise em geral feitas ao sexo, a que ele se opõe. Ele é contra a idéia da hipótese repressiva e afirma que a repressão ao sexo só estimulou ainda mais suas manifestações.

Mas, por que parece tão difícil fazer a inserção da "Orientação Sexual" na escola, mesmo depois de todo amparo legal para que isso aconteça? Bourdieu utiliza a noção de habitus, que, de certa forma, explica as dificuldades encontradas pelos professores em mudar uma prática que vem sendo executada há muito, sobre o trabalho com a sexualidade na escola. Observamos, durante a investigação, que existe um elo entre os conceitos incorporados pela escola, como locus de uma luta simbólica, estabelecida entre dominadores (docentes) e dominados (alunos). Nesse confronto, os dominadores têm conseguido impor suas verdades, seus tabus, sua crença acerca da sexualidade aos alunos.

Concluí-se que a abordagem do tema sexualidade pelos professores das séries iniciais do ensino fundamental nas escolas públicas da cidade de Montes Claros não tem atendido às necessidades de formação integral dos educandos e aos objetivos propostos nas diretrizes curriculares. Constatamos, na postura docente, que é considerada a importância do trabalho acerca do 
tema sexualidade, mas prefere-se não fazê-lo; é adotada uma postura pouco flexível, pois os profissionais se sentem, em muitos casos, constrangidos com tal abordagem; têm pouca preparação para o desenvolvimento de um trabalho consciente com o tema sexualidade, o que dificulta a articulação de uma prática coerente e transformadora; alguns desconhecem as diretrizes propostas pelos PCN's.

Os resultados desta pesquisa apontam que, no primeiro momento, é necessário que exista um planejamento e uma ação pedagógica sistemática, o que envolve espaço no currículo escolar. Pouco adianta um trabalho voltado apenas para o conhecimento do corpo ou para a higiene, como acontece freqüentemente. O trabalho de Orientação Sexual deve acontecer de forma permanente com os educandos, e o canal de debates e questionamentos deverá estar sempre aberto. Isso só acontecerá se o professor se sentir à vontade para abordar a questão; se o professor estiver em contato permanente com o tema, lendo, estudando, discutindo; se houver apoio de toda equipe pedagógica para a realização do trabalho.

Por fim, é importante refletir que o conhecimento escolar é dinâmico e não uma mera simplificação do conhecimento científico, que procura adequar-se à faixa etária dos alunos. $\mathrm{O}$ conceito de educar vai muito além do ato de transmitir aos alunos conteúdos acumulados historicamente.

O homem é um ser que precisa de orientação e informação. A diversidade atual exige dos profissionais da educação posturas mais amplas e, para tanto, é imprescindível a construção de um currículo articulado, a partir de experiências significativas. A ele compete dominar científica e politicamente o conhecimento sobre o processo educativo. Seu objeto de formação e atuação é o trabalho pedagógico no interior da escola ou fora dela. O ensino será, então, sua base obrigatória, apoiada no conhecimento, o que irá viabilizar a dinâmica do o fazer pedagógico.

É urgente que se pense na desconstrução da fragmentação dos conteúdos disciplinares, substituindo-o por um conhecimento significativo e globalizado que permita a integração do educando a seu contexto social. Para que isso aconteça, é inevitável a mudança do habitus cultivado tão severamente na instituição escolar.

\section{REFERÊNCIAS}

ARAÚJO, Ulisses. Temas Transversais e Estratégias de Projetos. São Paulo:Moderna,2003.

BOURDIEU, Pierre; PASSERON, Jean-claude A Reprodução. Rio de Janeiro:Editora Francisco Alves, 1975. 
BRASIL. Lei 9394, de 20 de dezembro de 1996. Diário Oficial da República Federativa do Brasil. Brasília - DF, 1996.

BRASIL, Parâmetros Curriculares Nacionais. Ministério da Educação e Desporto. Brasília - DF, 1997.

BUSQUETS, Maria Dolores et al. Temas Transversais em Educação: bases para uma formação integral. São Paulo: Ática, 2000.

FOUCAULT, Michel. História da Sexualidade I: a vontade de saber. Trad. de Maria Thereza da Costa Albuquerque e J. A. Guilhon Albuquerque. 10ª ed. Rio de Janeiro: Edições Graal, 1990.

História da Sexualidade II: o uso dos prazeres. Trad. de Maria Thereza da Costa Albuquerque. $5^{\text {a }}$ ed. Rio de Janeiro: Edições Graal, 1994.

FREIRE, Paulo. Pedagogia da Autonomia: saberes necessários à prática educativa. São Paulo: Paz e Terra,1996.

FREUD, Sigmund. Obras Completas. Volumes: VII, XIII, XVIII, XXI. Rio de Janeiro: Imago, 1980.

KUPFER, Maria Cristina. Freud e a Educação: o mestre do impossível. São Paulo: Scipione, 1997.

KUPERMAM, Daniel. Sexualidade e Educação. Rio de Janeiro: Gryphus,1999.

MIELNIK, Isaak.. Educação Sexual na Escola e no Lar: da infância à adolescência.10ª ed. São Paulo: IBRASA, 1990.

MURRAY, Edward. Motivação e Emoção. 10ª Ed. Rio de Janeiro. Quanabara, 1971.

ORTIZ, Renato. Pierre Bourdieu: sociologia. Ed. 2. São Paulo: Ática, 1980.

ROUDINESCO, Elisabeth. Dicionário de Psicanálise. Rio de Janeiro: Jorge Zahar Editor;1991.

SUPLICY, Marta. Conversando Sobre Sexo. Petrópolis, RJ: Vozes, 1983.

VYGOTSKY, Levi Semenovich. A Formação Social da Mente: o desenvolvimento dos processos psicológicos superiores. Ed. 6. São Paulo: Martins Fontes, 1998.

YUS, Rafael. Temas Transversais: em busca de uma nova escola. Porto Alegre:Artmed, 1998. 